\title{
Interview* $^{*}$
}

\section{Terry Cook}

Terry Cook has been Visiting Professor since 1998 in the post-graduate program in Archival Studies in the Department of History at the University of Manitoba, in Winnipeg, Canada, as well as an archival consultant, freelance editor, and writer. Has also taught archival science courses at the University of Michigan (United States) and Monash University (Australia). From 1975 to 1998, he was an archivist, manager, and senior executive at the National Archives of Canada (now Library and Archives Canada), leaving there as the director responsible for the appraisal and disposal of records in all media for Government of Canada. He also developed several influential National Archives' policies and implementation strategies, including those on macroappraisal, sampling, regional records, and electronic records. In his professional life, he has embrace both theory and practice, the concepts about archives and the strategies to make those concepts work in the real world of records and public administration. He has served eighteen years in total as General Editor of Archivaria, the national scholarly journal of the Association of Canadian Archivists; Editor of the Canadian Historical Association's Historical Papers - now its Journal; and Editor of its Historical Booklets series. He is also a member of editorial boards of archival scholarly journals in Canada, the United States, and Europe. In addition to publishing some eighty essays now appearing on six continents, he has written or edited five books, and is half way through the sixth, for publishers in France, Netherlands, United States, Spain, and Canada, plus authored numerous published guides and inventories for the National Archives of Canada. He has conducted multi-day institutes on appraisal, digital records, the postmodern archive, and archival ethics across Canada and internationally, especially several times in Australia, Ireland, Spain, and South Africa; given papers on every continent at numerous conferences; and delivered the plenary address to the International Congress on Archives' quadrennial meeting in Beijing in 1996 and to the ICA's Round Table at Quebec in 2007 and in Oslo in 2010. He visited Brazil in 1997, lecturing in Rio de Janeiro and Sao Paulo. From 1998 to 2006, he was the Association of Canadian Archivists' principal lobbyist preparing written

\footnotetext{
* Contributors to this interview: Solange Puntel Mostafa and Eduardo Ismael Murguia
} 
submissions and testifying before the Canadian Parliament on federal information policy issues, such as privacy, census records, digital media, and the creation of Library and Archives Canada. His current principal research interests are archival appraisal, the postmodern archive, archival theory, and the history of archives and of archival ideas. He is currently writing a book-length history of the Public/National Archives of Canada.

He earned a doctorate in History from Queen's University in Kingston, Ontario, in 1977. In his journey from historian to archivist, and from traditional archivist to postmodern archivist challenging many of the basic assumptions of his profession, his work has been recognized by many awards and prizes, including election as a Fellow of the Society of American Archivists, Fellow of the Canadian Society of Office Automation Professionals, and Fellow of the Association of Canadian Archivists. In 2010, he was elected as a Fellow of the Royal Society of Canada (the highest recognition for scholars and scientists in all academic fields in Canada), and the first scholar of archival science as a separate discipline to be so honoured.

InCID: You studied history for your doctorate and edited scholarly journals in history and wrote historical essays. Yet you have become an archivist, one especially known for radically rethinking our profession. What was the turning point for you? And how did history affect your views on archives?

Terry Cook: My special field of history was intellectual history, sometimes called the history of ideas. In history generally, and especially for intellectual history, the historian is always trying to answer the question, "why?" Why did something happen? Why did a person or group think or act in a certain way? Why did some ideas have influence and others fade away? Why did people in the past perceive economic or social conditions to be better (or worse) at some point than they actually were, and thus acted according to their perceptions, their beliefs, their assumptions, rather than respond to factual reality? Of course, the historian must know what happened, where, when, with whom, how. But to me, answers to these questions provide the framework, the context, for probing answers to the more interesting "why" questions. And so my turning point was when I started asking the same "why" questions early on in my archival career about archives, about archival ideas and processes, as opposed to asking them about historical research topics. For example, why was provenance such a venerated principle of our profession, of InCID: R. Ci. Inf. e Doc., Ribeirão Preto, v. 3, n. 2 p. 157-170, July/Dec. 2012. 
providing context for records by linking them to an office of origin, when there were, for complex government records, manifestly several offices of origin, not just one? Why was appraisal based on trying to mirror research trends in academic history when members of numerous other professions also used archives, and in increasing numbers, to say nothing of people outside formal academic professions: novelists, artists, chefs, playwrights, environmentalists? Why did the archival profession until about 20 years ago generally insist that the archivist was a neutral, objective curator, when archival appraisal, as but one example, was obviously both active and subjective?

Why did we insist on being perceived as curators of old records when we were ourselves very much shaping the archive. Rather than keeping archives, we were making archives.

And that was the main turning point for me: we as a profession were so obsessed with caring for the product (the record, the map, the photograph) that we overlooked the process (the recording or business function or activity behind the making of maps, photographs, or correspondence), including the process of archiving the archive. Why do we have the records we do in archives? Why do we describe them the way we do? Why do we adopt a professional mythology of passive curatorship rather than active mediation with the past? Why?, why?, why? To find answers, I turned to studying the history of archives and to questioning archival theory through a postmodern lens.

\section{InCID: You say that the foundational principle of our profession of provenance does not deserve the veneration that it widely receives. Tell me why you believe this.}

Terry Cook: The intent of provenance was to keep records in context, so that their value as evidence would be maintained. For wrapping records with rich context, whether old records or new digital ones, I am a great champion. The problem is that the archival pioneers defined context very narrowly as relating to the office of origin, a bureaucratic structure. I am more interested in what goes on inside that office. It is the functions, programs, and activities inside the office that generate records, not the office itself.

Moreover, the close one-to-one relationship assumed between function and structure in classic archival theory simply no longer holds true in modern organizations. The workprocess activities 
and the more macro-level functions that produce them now exist in many sub-offices, scattered across geographical space and across time, no longer reflecting a mono-hierarchical organization. The computer and telecommunications revolutions have radically accelerated this decentralization and diffusion, to a point where operational functions now cross all manner of structural or organizational lines. Peter Scott and Chris Hurley from Australia, most prominently, but increasingly joined by many others internationally, lamented decades ago the archival failure of forcing the many processes or multiple functions and activities for creating series and groupings of archives into one single administrative structure for describing archives, and calling this provenance, and the resulting records an archival fonds. Even back in Jenkinson's day, the official centralized registry system of records of his own British government did not actually operate in the classic way assumed by the pioneering archival theorists. It was stymied then, as recent research studies show, by informal conventions, localized practices, social expectations, and cultural norms: these form the real context of archives. These are the many variables that archivists themselves must research in order to understand real context, deeper context, and thus be able to perform all archival functions well based of a far better understanding of the context and thus meaning of records. The research knowledge that archivists thus gain about context will then be conveyed to researchers, so that archival records can be used with more subtlety and nuance.

In short, we archivists need to ask ourselves what happens to provenance when organizational cultures and work-place discourses are now transformed from vertical to horizontal, from controlling to collaborative, from stovepipes to networks, from executive fiat to internal consensus, from process-focused to conversation-enriched, with records created in these social realities and organizational cultures using these new protocols having radically different contexts, that is to say, a radically different kind of provenance, and yet we still think hierarchically, and arrange our archives and our descriptive tools according to structuralist hierarchical thinking? By so doing, archives are increasingly out of touch with reality of the context of records in modern administration when we link the provenance of records to a single structuralist entity. That approach, to me, speaking frankly, makes provenance irrelevant, and indeed dangerous, for our digital age. It is a burden from the past that we must reject. 
But if we interpret provenance differently not in terms of the administrative structures where the records creation and use took place, but rather focus first, and primarily, on the function of records creation and the multiple relationships of its original and continuing use, then new life is breathed into our central defining principle of provenance. The focus for provenance would shift to function, activity, discourse, and behaviour, rather than, as in the past, remaining centred on structures, offices, mandates, and origin. This opens description to presenting multiple origins and multiple orders for situating records rather than allowing only one view. This new approach would embrace extensive metadata and authority records documenting these deeper contextual elements enveloping the complex creation, uses, and relationships of records over their entire and continuing history, including after their entry to the archives. The new functional provenance would reflect the reality that records have detailed, contextualized, and inter-related histories, ever-evolving, opening up, rather than being closed down in fixed hierarchical orders. This new complexity of provenance has been called, by various archival writers, postcustodial or postmodern or functional; or has been termed as ambient or societal or virtual provenance; or has been described as a search for pattern recognition and narrative cohesion in the records-creation processes. In all these cases, the meaning of provenance is transformed from its structuralist origins to a iterative and ongoing discourse centred on functions, activities, processes, societal forces, and on the personal and organizational relationships and cultures that collectively cause records to be created, within and across constantly evolving organizational and personal lives. The new provenance offers multiple perspectives and many orders of value, rather than one fixed order.

\section{InCID: How then would you define provenance in this new contextual world of the digital age that you describe?}

Terry Cook: I would say that the principle of provenance should be centred on the context of those functions, processes, and activities of the person, group, or organization that causes records to be created, within and across constantly evolving organizations and personal lives, interacting with an ever-changing co-creators and users of the record, reflecting differing organizational and managerial cultures, or personal needs and psychologies, and often idiosyncratic and always 
dynamic conventions of work and human interaction appropriate for flattened, horizontal, networked, and (often) short-term activities.

Provenance, in short, is linked virtually, through fluid, dynamic, multiple relationships between creating or authoring activities and the resulting record and its many audiences.

Provenance links records to these multiple functional and activity relationships rather than primarily to its structural place of origin. The archivist's core intellectual and scholarly activity, then, in terms of description, is to conduct research into the history and character of these complex relationships, so that we may illuminate, across all archival functions, for ourselves and for our users, the rich contexts that surrounds records in the real world.

If I may add to that definition, if we do that, we give back to records their full provenance, thereby transforming information in our archives into possibilities of knowledge. If we archivists of the world can do that, if we can show to researchers and to society, the full rich provenance of records, then in fifty or five-hundred years, users of archives will trust the authenticity of the records as evidence, because the record will have been demonstrated, by archivists, to have emerged from a real, reliable, credible, and wellexplained context, rather than being forced into a simplistic structuralist framework.

\section{InCID: You mentioned that you reject the classic approach to archival appraisal that was articulated by TR Schellenberg of choosing records for archival long-term retention based on known or anticipated future research trends. Why?}

Terry Cook: Aside from the crystal-ball-gazing impossibility of trying to predict the future, Schellenberg's "value-through-use" approach to appraisal of mirroring or anticipating historical trends is fraught with conceptual difficulties: what about ever-changing trends in historiography that would render the resulting archival record a very fragmented patchwork, to say nothing of being skewered by lobbying by well-organized groups of users; what about a growing number of users of archives from a rich variety of non-historical disciplines (biologists, for example, or climatologists, or engineers, or nurses) for whom the archivist'shistorical training sheds little light; what about non-academic users (genealogists or railway or ship "buffs") and public policy users (such as those dealing with war criminals or various compensation claims for floods or 
similar disasters); what about archives as evidence for the protection of the human rights of citizens and Aboriginal peoples; what about archives being able to reflect those marginalized citizens in society who do not use archives and whose needs or interests would thus be excluded from any measurement of past use?

There are scores of examples in Canada at all levels of government of these kinds of issues. As German archival theorist Hans Booms brilliantly noted, linking appraisal to historical trends and patterns of use amounts to little more than History-educated and wellexperienced archivists employing "subtle intuition" based on their "ability to empathize with historical events ... even if they are generally unwilling to admit it." Various court cases in Canada dealing with missing records made it abundantly clear that appraisal based on empathy, intuition, and experience did not amount, in Booms' words, to "self-evident standards of value," to say the least. Such an approach was simply no longer ethically defendable in an era of greater accountability, including accountability for archivists.

And aside from these conceptual problems with a "use-focused" approach to appraisal, there are serious methodological problems as well. How could archivists themselves measure patterns of past use (even assuming the archival institution documented this process well over many years) as a valid predictor of likely "value" when there is no level playing-field on which such use occurs: some records being restricted from use by access provisions, physical frailty, or poor finding aids; and other records being very popular and heavily used in archival exhibitions and cited in many researchers' books and articles, even diffused by microfilming and digitization by archives, all this therefore creating a selfperpetuating loop of more and more use? As well, the use-based timetable for conducting archival appraisal was de facto at the end of the operational "life cycle" of the record, which was often several decades after the first documents were placed on the files being appraised. This extended passage of time did allow some historical perspective to develop more clearly, as Schellenberg hoped. But that luxury of time is no longer possible. Given the huge volumes of modern paper records and their much shorter retention periods to reduce massive storage costs, and especially the technological transience of their computergenerated counterparts, appraisal now has to occur before, at, or shortly after, the creation of the records, not some decades later. 


\section{InCID: You developed "macroappraisal" as a better way to conduct appraisal. Can you outline its main features.}

Terry Cook: In a single-sentence summary, macroappraisal assesses the societal value of both the functional-structural context and work-place culture in which the records are created and used by their creator(s), and the interrelationship of citizens, groups, organizations - "the public" with that functional-structural context. If traditional appraisal designates the long-term value of the content records, or series of records, for their potential research values, macroappraisal assesses the significance of the functional context of their creation and contemporary use. Appraisal is about records; macroappraisal is about their broader (or "macro") context.

Returning to this societal focus that forms the conceptual or theoretical underpinning of macroappraisal, sociologists have posited that all societies to varying degrees reflect a three-way interplay of social structures, social functions, and citizens (individually or as members of various social groups). Macroappraisal correspondingly seeks to suggest how such societal values may be determined in working reality by analysing the attributes, and points of special intersection (and sometimes conflict), between these three interrelated contextual entities: 1) the creators of records (that is, structures, agencies, offices, bureaucrats); 2) socio-historical processes (that is, functions, programs, activities, transactions - the services - which the state provides for citizens, and which citizens demand of government); and 3) the citizens, clients, customers, or groups upon whom these functions and structures impinge, and which in turn influence both function and structure, directly or indirectly, explicitly or implicitly. Macroappraisal requires archivists to research the nature of these agents and acts, and especially the interconnections and interrelationships between them, and then to assign greater importance, or "value," to certain functional-structural factors and citizens interactions as compared to others.

Macroappraisal is thus a provenance-based approach to appraisal, where the social context of the record's creation and contemporary use (not its anticipated research use) establishes its relative value. Macroappraisal thus also reflects the new, richer conceptions about provenance that I mentioned earlier in the interview.

This functional analysis by archivists means that the contextual milieu in which records are created is determined by all these factors: macro-functions, functions, sub-functions, structures and offices) and, in turn, by their organizational cultures, programs, activities, and transactions, 
and especially client interactions, as well as by records-creating processes, recordkeeping systems, and different recording media and recording technologies. By focusing archival appraisal research on analysing and evaluating - that is, "appraising" -- the importance of manageable numbers of these functions, programs, and activities, and citizen interactions, in the first instance, rather than on appraising billions of records, or tens of thousands of systems, series, and collections of records, the archivist is able to see the whole forest, rather than just a few trees. Seeing the whole context ultimately means that poorer and duplicate records are more easily identified and eliminated, and that the most succinct record in the best medium from the best location for a particular function is more readily targetted (or "appraised") for archival preservation. If assessing the value of records traditionally has been called "appraisal," then assessing this larger functional universe is appropriately termed "macro-appraisal." And if the research by the archivist into this functional-structural matrix is nuanced and thorough, the resulting records identified as archival will better reflect "societal values," simply because macroappraisal looks at the processes (and for documentary evidence of them) whereby society forms (and continually re-forms) itself accordingly to its own ever-changing values.

In doing so, macroappraisal therefore blends a "top-down" functional decomposition from society's broad wishes expressed through parliament in the functions and activities of the state with a "bottom up" attentiveness to citizen's corrective interaction with that state.

Moving from this theoretical model to implementable strategy, macroappraisal shifts the initial and major focus of appraisal from the record -- and any future research values it may contain -- to the functional context in which the record is created. Macroappraisal is thus centred on conceptual, virtual, or functional provenance, of the kind I discussed earlier.

Using research knowledge gained by the archivist's functional analysis, including an analysis of the interaction of function and structure, of organizational cultural dynamics, of records-keeping systems, and of citizen/client involvement and interaction with the institution or function, the archivist now asks, in performing an appraisal, three large sets of questions: 1) what are the most important functions and activities of the creator to be documented (rather than what documentation should be kept)?; 2) who - in articulating and implementing these key functions, programs, and transactions of the institution - would have had the primary responsibility to create a document, what type of document would it be, and with whom would that corporate person 
interact in either its creation or its later operational use?; and 3) how does the citizen interact with this functional universe, and how have citizens generally accepted and supported, or protested and challenged, the related programs and services? Only after these questions are answered through a macroappraisal research methodology can the archivist target realistically the actual records or series of records likely to have greatest potential archival value for the process of what, for distinction from macroappraisal, might be called "micro-appraisal" (that is, traditional appraisal applying such "criteria" as age, extent, uniqueness, time span, completeness, relatedness to other records, fragility, reliability, manipulability, etc.) at whatever greater level of detail they may warrant or resources may permit. Macroappraisal does not ignore microappraisal, or media-specific characteristics, but only puts them in a more logical place, or context. Of course, well before the microappraisal stage, the answers (based on archivists' research) to the three larger macro-level questions just mentioned means that large volumes of records can be destroyed without further investigation at the micro-level, thus saving agencies and archives considerable time, space, work, and money in the appraisal and records disposition process.

Forty years ago, Hans Booms challenged the archival profession to document society: actively, strategically, thoughtfully. With devastating effect, he showed that past appraisal theories left the archivist naked, an emperor with no clothes, selecting archives by intuition or apathy, privileging thereby powerful creators or influential users. Appraisal methodologies based on such theoretical assumptions are undefendable, and thus unaccountable, and I would add, unethical. The inevitable subjectivity and significant impact of undertaking appraisal might well be intimidating to archivists facing the challenge honestly, but setting out, Booms counselled, on such a "journey requires only that the traveller possess the insight and the will to draw the necessary conclusions and to act on them." Macroappraisal is one such journey.

\section{InCID: You mentioned that you have studied the history of archives? What have you learned in doing so?}

Terry Cook: My plenary address to the International Congress on Archives in Beijing in 1996 was an analysis of the history of ideas by archivists about archives, since the publication of the Dutch manual in 1898. That speech was much expanded into an article for Archivaria that has been translated into ten or more languages. I've also studied the history of archives generally in InCID: R. Ci. Inf. e Doc., Ribeirão Preto, v. 3, n. 2 p. 157-170, July/Dec. 2012. 
Canada, the National Archives of Canada itself in more detail, and biographies of some leading archivists. I should acknowledge that my linguistic limitations mean that I am basing my conclusions on the historical evolution of archival ideas and of the archival profession on historical investigations in the English-speaking world of Canada, the United States, Australia, New Zealand, and South Africa, as well as European ideas that have been translated into English primarily from Netherlands, France, Italy, and Germany. Nevertheless, my conclusions seem to have relevance, broadly speaking, in discussions with archivists from other linguistic areas, including Portugal, Spain, Norway, China, and so on. In my view, analyzing the history of archival ideas requires listening to the archival discourse of the time or place involved. Archival historical analysis requires revisiting the principal professional discussions that leading archivists had about their work and with each other. It requires hearing again, and understanding within the context of their time, and our own, their assumptions, ideas, and concepts.

Archival "theory" and archival "theorist" in this approach do not relate, respectively, to some immutable set of fixed principles and their constant defenders across varying realms of practice. That kind of historical perspective is rather too Positivist and outdated for a late twentiethcentury observer to adopt, even though that was the traditional archival position until around 1980. Rather, archival thinking over the past century or so should be viewed as constantly evolving, ever mutating as it adapts to radical changes in the nature of records, record-creating organizations, record-keeping systems, record uses, and the wider cultural, legal, technological, social, and philosophical trends in society. Archival ideas formed in one time and place reflect many of these external factors, which ideas are often reconstructed, even rediscovered in another time and place, or reshaped across generations in the same place. The best archival theorists are those who have been able to recognize and articulate these radical changes in society and then deal conceptually with their impact on archival theory and practice. That articulation forms our collective discourse, the meta-text or narrative animating our professional practice, and thus properly is the focus of an intellectual history of archives. 


\section{InCID: Are there certain historical phases in modern archives that you discern? What has our meta-narrative been over the past century?}

Terry Cook: I believe that there are four broad frameworks, or ways of thinking, or "paradigms," about archives - in both ideas and actions. Two of these we have passed through, a third we are now in, and a fourth is presenting itself very strongly, and is our hope for the future. I can only summarize them here, and refer readers to a forthcoming article in Archival Science where I deal with this in much more detail. I have labelled these four as evidence, memory, society, and community.

The first archival paradigm was centred around guardianship of a "natural" residue of older records as evidence, and the principal professional focus of the archivist, as impartial custodian, was on arrangement and description to put that juridical residue in context for use and understanding by posterity as authentic and reliable documentary sources.

Evidence was the key concept of the first paradigm, and this concept dominated professional discourse until the 1930s, and continues to the present as an important archival concern. In the English-speaking world, Hilary Jenkinson was the key thinker.

The second archival paradigm was distinctively concerned with appraising records as historical sources, with the historian-archivist subjectively creating a cultural memory resource rather than guarding an inherited juridical legacy of older evidence. This memory resource was managed more efficiently for the ever-larger holdings using modern business tools and processes, to support new approaches to appraisal and description. The resulting archive was, of course, still evidence of human and organizational activity, but the context in which that evidence was now created, appraised, acquired, described, and understood had been transformed. Memory is the key concept of the second archival paradigm, which flourished from the 1930s to the 1970s, before showing its weaknesses. Theodore Schellenberg was the key thinker here.

The third archival paradigm was distinctively focused on archives as a societal resource, one that was discerned, appraised, acquired, and described by archivists as records experts, in their own right, for a wide range of uses, a societal resource that increasingly respected the pluralistic and ambiguous nature of the postmodern and digital world rather than the monolithic patterns that had dominated earlier archival frameworks, whether juridical or historical. Archives also moved 
from being a cultural and heritage resource underpinning the academic elite to becoming a societal foundation for identity and justice.

The archivist's own identity was anchored in being the expert leading society to find its identity through shared memories grounded in more sophisticated conceptions of evidence.

Identity is the key concept of the third paradigm - the search for the archivist's own identity as a conscious mediator aiding society in forming its own multiple identities through recourse to archival memory and as an active agent protecting evidence in the face of the blistering complexity of rapidly changing societal organizations and digital media.

The challenge facing archivists now in 2012 is to achieve more democratic, inclusive, holistic archives, collectively, listening much more to citizens than the state, as well as respecting indigenous ways of knowing, evidence, and memory, than occurred in the first three paradigms. For records still acquired by mainstream archives, as Helen Samuels' documentation strategy long ago articulated, appraisal and acquisition would be collaborative and cooperative and interactive, online, and so too would be description and preservation, in order to find the best location for preserving the best records with the fullest participatory-illuminated context - a Wikipedia for archival sources. Beyond what established archives themselves acquire, however, there are vast numbers of records remaining in communities that shed important light on society. Rather than taking such records away from their communities, the new model suggests empowering these communities to look after their own records, especially their digital records, by partnering professional archival expertise and archival digital infrastructures with communities' deep sense of commitment and pride in their own heritage and identity. Community is the key concept of the fourth archival paradigm now coming into view, a democratizing of archives suitable for the social ethos, communication patterns, and community requirements of the digital age.

So, in conclusion, I believe that archival paradigms have ranged through four phases: from juridical legacy to cultural memory to societal engagement to community archiving. The archivist has been transformed, accordingly, through these four phases from passive curator to active appraiser to societal mediator to community facilitator. The focus of archival thinking has moved likewise from evidence to memory to identity and community, as the broader intellectual currents in society have changed from pre-modern to modern to postmodern to contemporary. Of course InCID: R. Ci. Inf. e Doc., Ribeirão Preto, v. 3, n. 2 p. 157-170, July/Dec. 2012. 
there is overlap. Strands from all four mind-sets are interwoven. This discussion is about emphasis, not rigid definition. But in community archiving, we archivists may be able find a new identity that reconciles our twin missions (and often warring traditions) of evidence and memory. And by so doing, we may better understand and thus enrich our own sense of being a community of archivists. That community should be one capable of embracing differences rather than founded on either a single animating mythology or the exclusion of those different and "other," whether evidence advocates downplaying memory and dismissing its advocates as un-archival mediators or, vice versa, memory advocates dismissing evidence guardians as narrowly legalistic. By anchoring its increasingly diverse activities and approaches through an engagement with lived communities and their evidencememory-identity practices, archival practice (and identity) can itself remain plural and diverse without becoming simply fractured into disconnected camps or riven by struggles for supremacy of one school of thinking versus another. Community archiving, as a model, offers much to archivists, even as archivists have much to offer to community archiving.

I believe that community archiving holds out the promise of an increased capacity in our archival community to harbour plurality, diversity, and difference (both in terms of our own divergent practices, across space, time, and traditions; and in terms of the very different social and cultural communities with which we engage). Seeing archival paradigms as changing through time, through the study of archival history, as each era interprets anew evidence and memory, and thus redefines archival identity and its relationship with social communities, liberates us to embrace new directions yet again for the digital era. The alternative, as Canadian archival theorist Hugh Taylor warned us, is to risk becoming fossils floating in the stagnant backwaters of social irrelevancy.

Interview posted: Nov. 2012

InCID: R. Ci. Inf. e Doc., Ribeirão Preto, v. 3, n. 2 p. 157-170, July/Dec. 2012. 